\title{
Equivalence of two manufacturers' precision food pellets for rats
}

\author{
WILLIAM M. BAUM \\ University of New Hampshire, Durham, New Hampshire
}

\begin{abstract}
Precision food pellets made from purified ingredients by two different manufacturers $(P$. J. Noyes Company, Inc. and Bio-Serv, Inc.), and advertised as dust-free and nutritionally complete, were compared as reinforcers of leverpressing in rats. Single schedules (a variable interval [VI] of $30 \mathrm{sec}$ and a fixed ratio of 20 ) were used to compare ability to maintain moderate and high response rates, and concurrent VI schedules were used to assess preference. The two pellets maintained equivalent moderate and high response rates on the single schedules. In the concurrent schedules, 3 out of 4 rats showed a small preference for the Bio-Serv pellets. Although both pellets performed adequately in normal humidity, high humidity caused the Bio-Serv pellets to soften and occasionally to be crushed in the pellet dispenser. Their softness may have been the reason they were preferred. The two pellets can be regarded as generally equivalent, except in high humidity. The only experiments in which they might not be used interchangeably are those involving choices between different reinforcers.
\end{abstract}

In studies of operant behavior, many different reinforcers have been used, but food probably has been the all-time favorite. For rats in particular, a variety of precision food pellets for automatic dispensers is available commercially, and since they all seem to reinforce behavior, there has been little tendency to standardize ingredients.

Since food pellets used in an experiment can make up a sizable portion of a rat's daily intake, it might be desirable for these reinforcers to be not only palatable but nutritious. Two manufacturers of precision pellets-P. J. Noyes Company, Inc. and Bio-Serv, Inc.-have begun selling pellets that they advertise as nutritionally complete. The P. J. Noyes Company follows the formula suggested by the American Institute of Nutrition (1977, 1980), whereas Bio-Serv follows the guidelines suggested by the National Research Council Subcommittee on Laboratory Animal Nutrition (1978). Thus, although the two diets are not identical, it seems likely that both are fully nutritious.

Whether or not these standard-diet pellets become the norm in operant research, it would be useful to know the extent to which the two manufacturers' pellets produce equivalent effects and can be used interchangeably. The present study undertook to compare the two pellets as reinforcers of rats' leverpressing. If they are equivalent, they should maintain moderate response rates on a variableinterval (VI) schedule and high response rates on a fixedratio (FR) schedule. If they are interchangeable, they should reveal no preference in concurrent VI-VI schedules.

Correspondence and requests for reprints should be addressed to William M. Baum, Department of Psychology, University of New Hampshire, Durham, NH 03824-3567.

\section{METHOD}

\section{Subjects}

Four male hooded rats bred at the University of New Hampshire from Long-Evans stock were maintained at $80 \%$ of their free-feeding weights. All were 7 months old at the beginning of the experiment. They were housed individually in standard stainless steel cages in an airconditioned colony room lighted brightly from 2300 to $1100 \mathrm{~h}$ and dimly from 1100 to $2300 \mathrm{~h}$. Water was available continuously.

\section{Apparatus}

The experimental chamber conformed to the standard design for rats. On the front wall were mounted two microswitch levers and a single centrally located food hopper. Two pellet dispensers (Gerbrands Co.) were connected to the food hopper. The chamber was housed in a plywood outer box located in a windowless room. The experiment was controlled by electromechanical equipment in another room.

Reinforcers consisted of $45-\mathrm{mg}$ dust-free precision pellets obtained from the P. J. Noyes Company (Formula P/AIN-76A) and from Bio-Serv (Product F0021). The Noyes pellets were advertised as conforming with the standard diet of the American Institute for Nutrition (1977, 1980). The Bio-Serv pellets were advertised as conforming with the guidelines of the National Research Council Subcommittee on Laboratory Animal Nutrition (1978).

\section{Procedure}

With rare exceptions, sessions were conducted daily at about $1400 \mathrm{~h}$, during the dim period of the colony light cycle. A session ended when 60 reinforcers had been obtained. 
Table 1

Conditions of the Experiment and Number of Sessions of Exposure

\begin{tabular}{lclc}
\hline Schedule & Lever and Feeder & Pellets & Sessions \\
\hline VI 30 sec & Left & Noyes & 24 \\
VI 30 sec & Left & Bio-Serv & 14 \\
VI 30 sec & Left & Noyes & 14 \\
FR 20 & Right & Bio-Serv & 16 \\
FR 20 & Right & Noyes & 17 \\
FR 20 & Right & Bio-Serv & 17 \\
Concurrent & & & \\
VI min & Left and Right & Noyes (L), Bio-Serv (R) & 10 \\
VI min & Left and Right & Bio-Serv (L), Noyes (R) & 10 \\
\hline
\end{tabular}

After hand-shaping to press both levers, the rats were trained for two sessions with continuous reinforcement for presses on either lever. The right-hand lever and feeder were then disconnected and five sessions of continuous reinforcement on the left lever were given. All initial training was conducted with Noyes pellets. Following initial training, the first condition of the experiment (VI $30 \mathrm{sec}$, Noyes pellets) began.

Table 1 shows the conditions of the experiment and the number of sessions conducted in each condition. Conditions were maintained for about 2 weeks for the single schedules and 10 days for the concurrent schedules, regardless of whether performance appeared entirely stable. The first condition was extended because of intermittent apparatus malfunctions, which were eliminated after the first 10 days. The VI schedules were constructed according to the method suggested by Fleshler and Hoffman (1962)). The first FR condition (Bio-Serv pellets) began with a single session of exposure to FR 15 , after which the schedule remained FR 20. The equal VI schedules in the last two conditions were intended to ensure that the two pellets were delivered in equal numbers, eliminating any dependence of preference on a difference in consumption (Rachlin, 1976). Measured preference would then depend only on differences between the pellets.

\section{RESULTS}

On the whole, both pellets performed satisfactorily from a mechanical point of view; as advertised, neither generated significant dust. While the concurrent schedules were being run, the weather turned extremely hot and humid, with the result that, despite air conditioning, the laboratory became more humid than usual. Under these conditions, the Bio-Serv pellets became soft and were sometimes crushed in the feeder, whereas the Noyes pellets remained firm and none were crushed.

Figure 1 shows the response rate averaged across the four rats for the first three conditions (VI $30 \mathrm{sec}$ ). Because of the apparatus malfunctions during the first 10 days, only the last 14 days of the first condition are shown. The averages reveal that no systematic changes in response rate occurred as a result of the changes of reinforcer. When Bio-Serv pellets were introduced, the response rate went up for 2 rats, down for 1 rat, and remained the same for 1 rat. When Noyes pellets were restored, the rate went down for 3 rats and up for 1 rat. Only 1 rat (Rat 2) showed any consistency $-\mathrm{a}$ response rate about 5 presses $/ \mathrm{min}$ higher for the Bio-Serv pellets.

Figure 2 shows the average response rate for the three FR-20 conditions. During the first condition (Bio-Serv pellets), the response rate at first fell from the level maintained by VI $30 \mathrm{sec}-$ about 50 presses/min-to about 25 presses/min, probably because of the switch from the left lever and feeder to the right lever and feeder. After the first few sessions, the rate rose to a high level that was characteristic of ratio schedules.

The changes of reinforcer appeared to have no effect on FR-20 performance. The pattern of increasing response rate across the three sets of points in Figure 2 appears smooth, with no anomalies at the condition transitions. Response rate increased with the switch to Noyes pellets (second condition) and increased again with the switch back to Bio-Serv pellets, but both increases appeared only to reflect the larger pattern of the rise to a high stable rate. The data of all 4 rats conformed to the same pattern as the average.

Figure 3 shows the response ratios that were obtained in the concurrent schedules. The rats' data are presented individually, because averaging would mask their idiosyncratic position biases. Rats 1 and 2 preferred the right

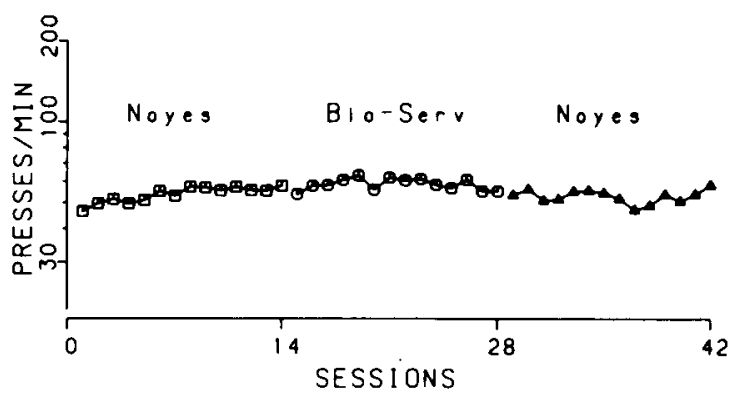

Figure 1. Average response rate on a VI $30-\mathrm{sec}$ schedule with Noyes pellets and Bio-Serv pellets as reinforcers. Different symbols indicate different conditions. Note logarithmic $y$-axis.

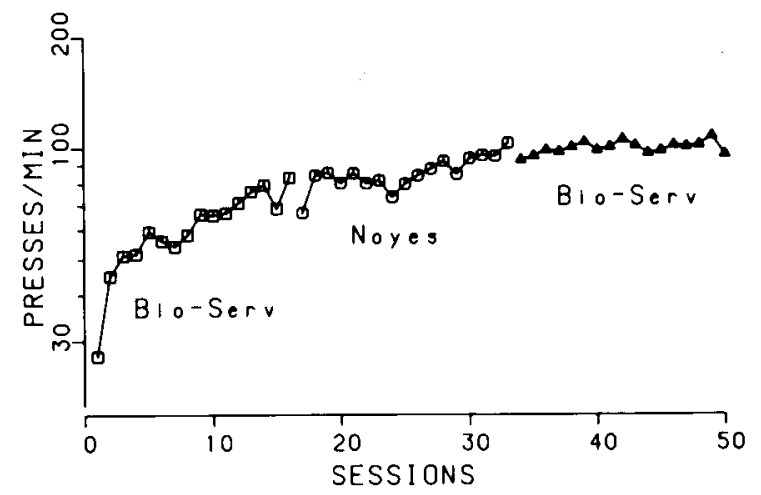

Figure 2. Average response rate on FR 20 with Noyes pellets and Bio-Serv pellets as reinforcers. Different symbols indicate different conditions. Note logarithmic $y$-axis. 


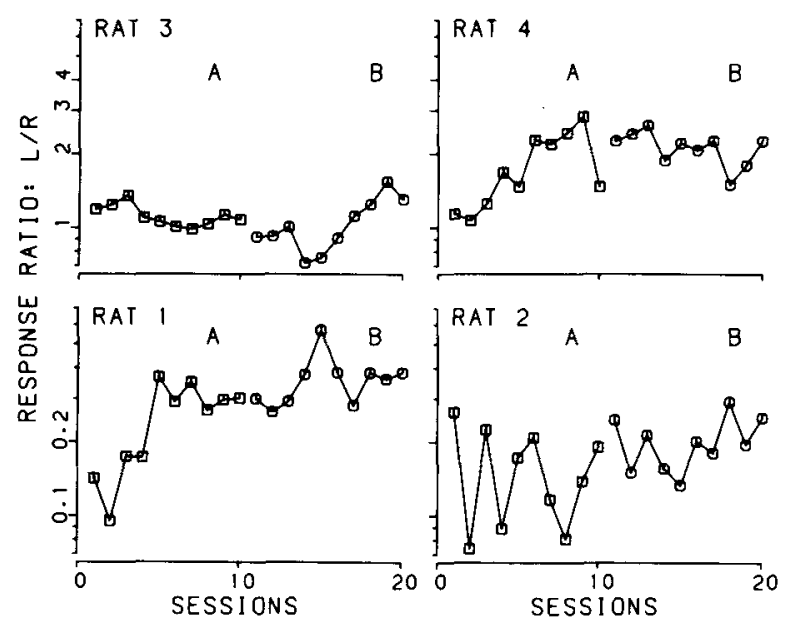

Figure 3. Choice between Noyes pellets and Bio-Serv pellets in concurrent VI $1 \mathrm{~min}-V I 1 \mathrm{~min}$ : ratio of presses on the left lever to presses on the right lever. A (squares): Noyes pellets left, Bio-Serv right. B (octagons): Bio-Serv pellets left, Noyes right. Note logarithmic $y$-axis.

lever and feeder (ratios less than 1.0), whereas Rats 3 and 4 preferred the left lever and feeder (ratios greater than 1.0). When the reinforcers were switched, so that the BioServ pellets were on the left and the Noyes pellets on the right, 3 rats' (Rats 1, 2, and 3) preference shifted a little toward the left, whereas 1 rat's (Rat 4) preference shifted slightly toward the right. Although it might be said that, on the balance, 3 out of 4 rats weakly preferred the BioServ pellets, since all of the changes were small, with an overlap of ratios between conditions, it is doubtful that any of the changes should be considered significant.

For all rats in both choice conditions, the distribution of reinforcers between the two levers closely approximated equality, as the equality of the schedules required. Small deviations occurred in individual sessions, but across sessions, the average number of pellets delivered never deviated significantly from 30 per lever.

\section{DISCUSSION}

On the whole, the Noyes pellets and Bio-Serv pellets appeared to function equivalently. They maintained about the same response rates on a VI 30-sec schedule (Figure 1), and no change in response rate on FR 20 appeared to be caused by switching pellets (Figure 2).

The reason that 3 rats may have showed a small preference for the Bio-Serv pellets (Figure 3) is unclear. Since even a human observer could distinguish the pellets by sight, smell, and taste, probably the pellets were readily distinguishable to the rats, and perhaps the Bio-Serv pellets were more palatable-they seemed sweeter to a human observer. Alternatively, since the Bio-Serv pellets softened during this phase of the experiment because of humidity, the preference might have occurred because they were easier to chew and swallow than the Noyes pellets. Whatever the reason, the preference suggests that in ex- periments assessing preference between qualitatively different reinforcers, the two pellets may not be perfectly interchangeable. In such experiments, one type cannot simply be substituted for the other because it might be preferred to a different extent to any third reinforcer. Choice experiments in which the alternatives deliver the same reinforcer should present no such problem-the two ought to be interchangeable, just as they are in singleschedule experiments.

The assessment of preference could have been improved in one respect. It would have been useful to record the amount of time spent responding at each lever, in addition to counting the number of responses. If the ratio of responses favored one reinforcer, it could be for either of two reasons: (1) More time and more responses could have been allocated to that lever, or (2) the same amount of time could have been allocated, but the response rate while responding (i.e., the local response rate) on one lever could have been higher (Baum, 1976; Baum \& Rachlin, 1969). Although the smallness of the preferences in Figure 3 indicates that no such distinction could be made in the present experiment, future tests of this sort might plan for it by recording both time and responses.

The degree to which humidity in the laboratory might be a problem depends on two factors: the humidity of the outdoor air and the capacity of the air-conditioning system. Although the circumstances under which the BioServ pellets softened were unusual for New Hampshire, they might be more common in other locations. If the outdoor humidity is often high, and the air-conditioning is inadequate to stabilize humidity in the laboratory, then humidity would be a factor in choosing between the two brands.

In sum, there appears to be little reason for experimenters to prefer one pellet over the other, with one exception: If humidity fluctuates in one's laboratory, then one might prefer the Noyes pellets for their ability to stay firm.

\section{REFERENCES}

American INSTItUTE of NuTrution (1977). Report of the AIN ad hoc committee on standards for nutritional studies. Journal of Nutrition, 107, 1340-1348.

AMERICAN INSTITUTE of NuTrition (1980). Second report of the ad hoc committee on standards for nutritional studies. Joumal of Nutrition, 110, 1726.

BaUM, W. M. (1976). Time-based and count-based measurement of preference. Journal of the Experimental Analysis of Behavior, 26, 27-35.

BaUm, W. M., \& Rachlin, H. C. (1969). Choice as time allocation. Journal of the Experimental Analysis of Behavior, 12, 861-874.

FleshleR, M., HofFMAN, H. S. (1962). A progression for generating variable-interval schedules. Joumal of the Experimental Analysis of Behavior, 5, 529-530.

National Research Council Subcommittee on Laboratory ANImal Nutrition (1978). Nutrient requirements of laboratory animals (National Research Council Committee on Animal Nutrition: Recommended nutrient allowances for domestic animals, No. 10). Washington, DC: National Academy of Sciences.

Rachlin, H. (1976). Behavior and learning. San Francisco: W. H. Freeman.

(Manuscript received October 25, 1990; revision accepted for publication February 11, 1991.) 